\title{
Performativity on the Margin: Pornography: The Musical (2003)
}

Catalin Brylla (University of West London)

\begin{abstract}
Brian Hill's musical documentaries embody the essence of Judith Butler's notion of 'performativity' as the discourse used in identity formation. By asking his characters to sing their stories in addition to traditional interviews, Hill creates multiplescreen identities, which elicits an embodied intimacy that is as much about freeing marginalised people to enact themselves in front of the camera as it is about revealing the director's own performance. This article uses a cognitive framework to explore how Hill's documentary, Pornography: The Musical (2003), leads the spectator to challenge existing social stereotypes of sex workers, as well as schematic ideas about traditional documentary form and function.
\end{abstract}

Keywords: documentary; performativity; stereotypes; musical; cognitive theory; spectatorship

\section{Introduction}

Since the 1990s, British documentary director Brian Hill has been exploring the expressive dimension of documentarystorytelling as a way of giving a performative voice to under-represented or misrepresented social actors. Pornography: The Musical is Hill's most controversial and also most stylistically expressive film, ${ }^{1}$ offering a complex mix of studio performances (in which the characters sing and perform their stories), conventional interviews and sporadic observational inserts. Summed up in publicity as a 'sideways peep at the British porn industry and the women who work in it', ${ }^{2}$ the film's strength lies in its microscopic endeavor to give seven women the opportunity to express their views about the industry, resulting in a filmic collage of subjective, and at times contradictory, character portraits, rather than factual reportage. As in previous films, Hill collaborated with poet Simon Armitage, who wrote the lyrics for the musical performances based on preliminary interviews with the characters. Tailoring each musical performance to an individual character through the lyrics, music and set design increases the subjectivity of each character portrait. This mode of representation provides women in the sex industry with a distinct voice and 
challenges the hypocrisy surrounding pornography: a popular, widespread commodity emanating from a socially marginalized industry.

Although the unique character of Hill's musical documentaries has been thoroughly discussed in relation to production practices, formal strategies and media responses, ${ }^{3}$ । want to shift the focus to the spectatorial dimension, using a pre-dominantly cognitive approach to hypothesise how the film's idiosyncratic style and narrative potentially reconfigure existing social stereotypes about sex workers and schematic expectations about documentaries. Nevertheless, the broad theoretical framework for this endeavour is necessarily interdisciplinary, as it needs to amalgamate the psychological with sociocultural accounts of subjectivity and identity formation. To this end, this article avails itself of a range of methods and models: performativity, content analysis of other documentaries, textual analysis, cognitive schemas, social stereotype formation, authorial reflexivity and embodied metaphors. This bricolage approach aims to prevent the generation of purist exegeses, thus following Charles Percy Snow's call for a mediating agent that transcends the parochial schism between sciences and the humanities in order to pragmatically grapple with global issues. ${ }^{4}$

Judith Butler's concept of 'performativity' is an effective paradigm to frame the study of the on-screen formation of subjective identities in documentary. ${ }^{5}$ Butler holds that acts of communication do not merely transmit a message but also construct and perform the identity of the transmitter. The performed discoursethat forms one's identity is in general determined by contextual norms, relating to, for example, society, culture and particular situations. In this sense, performativity reverses the popular notion of a fixed, inbuilt, invisible identity as the source ofour external actions; rather, our speech, gestures and general behaviour constructand simultaneously perform that identity. As Butler succinctly puts, there 'is nosubjectpriorto itsconstruction' 6 Although Butler's performative focusislargelyon gender, I adopt her concept to map embodied human identity in general, in which gender is merely one discursive aspect. Essentially, when applied to Pornography: The Musical, performativity helps explain the viewer's experience of the characters' various on-screen behaviours while singing or being interviewed, which determines the spectatorial understanding of the multiple, and at times incongruent, character identities embedded in the film text.

Generated through the hybridisation of documentary and musical, this constant flow of 
multiple identities attributed to the same narrative character defies the notion of fixed schematic characters. As Derek Paget and Jane Roscoe indicate, this multi- layered identification defies traditional templates, which through other films about sex workers have fossilised into formulaic narrative and social stereotypes. ${ }^{7}$ This applies equally to the film's overt performative construction, an authorial eccentric- ity that rejects traditional documentary form. Examples of documentary characters being asked to perform past or imaginary events in the context of the filming process are relatively rare, and notable examples include Jean Rouch's ethnofiction Moi un Noir(1958), Rithy Panh's S21: The Khmer Rouge Death Machine (2004) and Joshua Oppenheimer's Act of Killing (2013). Such documentaries reflexively reveal and thematise the concept of performativity, not through rhetorical or didactic means of factual exposition, but through the elicitation of embodied experiences. Bill Nichols argues that, 'performative documentaries give added emphasis to the subjectivequalities of experience and memory that depart from factual recounting ${ }^{\prime}{ }^{8}$ Indexical knowledge is pushed into the background and the question of whether the filmprovides a truthful portrayal of the real-life characters is arguably overwritten bytheir complex and non-schematic personalities on screen.

Thefollowing discussionexplores, fromanaudience'sperspective, howthescreen characters' and the filmmaker's performativity challenge societal preconceptions; thus, Pornography: The Musical can be considered as a quasi-exhibitionistic social construct, and by implication, social commentary. The first part provides a briefcontent analysis of other documentaries about the porn industry, highlighting how narrative techniques embed certain ideas of sex workers in the spectator's socialawareness of this community. The mapping of these preconceived ideas allowsthe subsequent hypothesisation about how the multiple, performed identities inPornography:TheMusicalreconfigurespectatorial schemas. The subsequentsection examines how the film's reflexive and highly stylised authorship mediates the complex and ambiguous merging of two seemingly incompatible genres, thus furtherchallenging documentary norms and related cognitive schemas. Hill's overt author- ship also creates thematic associations through the use of audio-visual metaphorsthat elicit embodied experiences in the viewer, in particular the metaphors of 'com- modification' and 'marginality'. In sum, this article aims to provide a framework for examining the social context and implications of documentaries that experimentwith performative enactments of marginalised communities. 


\section{Representation of Characters}

The content analysis of a particular body of films representing the same social group can identify spectators' schematic understandings - that is held stereotypes - ofthat group, which are especially formed through the repeated portrayal of similarnarrative scenarios. Popular documentaries about the porn industry distributed inthe United States and the United Kingdom include Sex: The Annabel Chong Story (1999, Gough Lewis); Thinking XXX (2004, Timothy Greenfield-Sanders); Inside Deep Throat (2005, Fenton Bailey, Randy Barbato); The Dark Side of Porn (2005, documentary series, Channel 4); 9 To5: Days In Porn (2008, Jens Hoffmann); After Porn Ends (2012, Bryce Wagoner); and Hot Girls Wanted (2015, Jill Bauer, Ronna Gradus).

The most prominent common denominator in these films is their journalistic approachtothetopic, manifested inan investigativestylethat producesaconstant flow of factual exposition about the industry and the characters' lives. The aim is to 'penetrate' the pornindustryinordertoilluminate its structures and mechanisms, and theirimpactonthe peoplewhoworkinit. Almostall the filmsfeatureacollage ofcharacter portraits, presented as a representative sample of sexworkers, whose lives are strongly narrativised. Narrative formulas seek to reveal the motivations behind the characters' employment in the porn industry and to mediate the emotions this raises through a pursuit of clear goals, such as finding a way out of theindustry, battling alcohol addiction, reconciling porn with family values or simply climbing the industry's career ladder. Two distinct features of this narrativization process are, first, the exposition of (usually negative and traumatic) experiencesin childhood or adolescence which apparently helped propel the characters intothe industry, and second, 'where-are-they-now' epilogue title slates that tell theaudience about the lives of the characters at the time of the film's completion, with a particular emphasis on whether they have left or still remain in the industry. This examination of characters' lives through three-act narratives (pastpresent-future) is symptomatic of what Michael Renov calls documentary's 'acquisitive, totalizing quest for knowledge', turning 'subjects' into 'objects of knowledge'. 9

As Sarah Cooper argues, documentaries generally privilege universal arguments or generalisations over individual difference or particularity due to a 'tendency to situate the particular in terms of broader social and political issues' ${ }^{10}$ Rather than providing a more intricate understanding, this tendency actually limits audiences' knowledge because the inevitable formation of character stereotypes elides nuance. One example is the use of 
valence, which is reinforced by filmmakers who attempt to draw out their characters' opinion of the industry. For instance, in After Porn Ends, the interviews often push the characters into responding with either positive or negative evaluations: 'Idon't have many regrets... so much positive stuff came out of it' (Randy West) or 'I regret doing porn and I never thought I would be who I became' (Houston). Whilenegativeevaluations-stressing the prevalence of dehumanisation, exploitation and drug abuse - appear to dominate, there are occasional hyperbolically celebratory voices that emphasise the glamour and wealth of the industry, most notably in Thinking XXX. This binary opposition between demonisation and idealisation is reflected in the starkly negative or positive emotions expressed by the characters on screen and reinforced by audio-visual techniques (dark/light lighting and sinister/upbeat music). The impression of a universal, totalised knowledge isachieved through the display of strong human emotions that resonate with a wide audience and clear-cut social commentaries about the industry. Sex: The Annabel Chong Story is the most iconic example of this strategy of narrativisation through universalcharactertraits, emotionsand behaviours. Chong isalternatelyrepresented as either the idealised porn star or the exploited, guilt-ridden woman who suffersfrom depression, self-harm and substance abuse.

There is no inherent problem with film characters expressing clear-cut emotions or opinions, but, taken as a whole, all the above films appear to use virtually the same narrative strategies in pursuit of a wide audience and commercial success. After all, emotions and clear insights into a socially stigmatised industry are generally well received by festival viewers and broadcasters. These commercially tried-and-tested narrative formulas, however, create a fairly coherent body of representations ofsex workers, demonstrating Homi Bhabha's concept of 'fixity' in the construction of 'otherness' through constant repetition and rigidity. ${ }^{11}$ Instead of highlightingindividual nuances and ambiguities, characters are treated as a synecdoche for the sex industry in general, a reductive shortcut that inevitably leads to stereo-types that emphasise collective differences between 'them' and 'us'. From a cultural studies perspective, Richard Dyer explains that stereotypes are the 'fixed, clear-cut and unalterable' schemas attached to those who are excluded by the normativerules of society. ${ }^{12}$ These schemas are simplistic mental representations of another marginalised social or cultural group, and they often operate through valenced (negative/positive) stereotypes and, in relation to the porn industry, a plethora ofother binaries, such as wealth/poverty, good health/addiction, success/oblivion 
and socialacceptance/rejection. ${ }^{13}$

Pornography: The Musical, on the other hand, deliberately omits the universalisation of mediated knowledge about the porn industry and its social actors. Onefeature of the film is the lack of clearly narrativised character trajectories. Ratherthan being plot-driven, characterisation derives from fragmented performative acts (both in the musical and interview scenes) as particular moments in space and time; Hill's project eschews scenes that are merely functional in terms of larger developments inherent to archetypical character journeys. The film is thus an assemblage of vignettes, resulting in what Nichols calls a 'mosaic narrative', in which the 'whole is not organized as a narrative but more poetically, as a mosaic; only the parts have a diegetic unity'. ${ }^{14}$ This unity of particular moments is reinforced by the singingscenes, which are presented like randomly appearing music videos, each with a clear micro-narrative. Greg Smith observes that episodic narrative structures in non-plot driven documentaries focus on self-enclosed fragments, singular moments that have the potential to highlight the performativity of certain actions without setting upany character development or cause-and-effect chain. ${ }^{15}$ In this way, a conventional narrative arc is foreclosed.

Furthermore, the episodes (as well as the characters' entire storylines) start and finish in medias res. Epilogue slates or questions about the characters' futures(staying in or getting out of the industry) are absent, as is the deliberate investigation into their past to uncover how they came to be in the porn industry, a further point of contrast to the aforementioned orthodox porn industry plots. Some charactersdo not even touch on the past, while others casually mention or hint at their reasons for being in the industry. Rachel, for example, says succinctly that she has always nurtured the fantasy, and now she is living it. Faye even picks up on the stereotype of trauma, expressing the belief that most people would assume that traumaticchildhood events pushed her into porn, but in fact she was very shy as a child and did not start experimenting with sex until much later; she now regards it as a fulfilled pleasure. Kelly is the only one who extensively ponders over her past, but again with a good portion of self-irony, saying that her story is so clichéd that it is hardly worth telling. Her story is indeed experienced in a clichéd manner by the spectator in the film's very first musical act, in which Kelly sings about the stages of her progress in the industry, as her body becomes objectified and she realises the industry's lack of love and compassion, summarised by the refrain, 'Where is the heart?' 
Several characters do, of course, express views that recall the stereotypes mentioned earlier, such as Kelly's overall disillusion with, and Michelle's overall glorification of, the industry. Interestingly, however, through the film's performativity, the epistemic nature of their testimonies means they depart from any'factual recounting', as in Nichols's notion of performativity. Once the musical documentary genre is introduced to the audience, the factual veracity of the characters' oral testimonies is no longer a major element of spectatorial appraisal. More so, the characters are experienced as performing not just in front of but for the camera,the filmmaker and ultimately the audience. The overly clichéd musical rendition of Kelly's story of her past is a case in point. Her performance is genuine as a temporary performance, but it only reveals one particular identity of a character that isneither fixed nor veridical since it competes with other constructed identities. This exemplifies Pornography: The Musical's strategy of bypassing stereotypical portrayals. Each character performs at least two identities: one is constructed through the conventional documentary techniques of interviews and occasional fly-on-thewall inserts, the other through the techniques of music-video production.

The relationship between these two aesthetic modes is precarious and ambiguous. In terms of audience address, Richard Dyer argues that in film musicals the verisimilitudinous nature of the narrative contradicts the imaginary nature of themusical interludes. ${ }^{16}$ In Pornography: The Musical this contradiction is even more pronounced, given the perceived factuality of the interview narratives. The musical interludes follow no apparent convention, but seem tailored to each unique character. They alternate between fantasies, flashbacks, flashforwards and everyday activities, and they appear at times contradictory, at times confirmatory, and attimes ambiguous in relation to the narrative. For example, in her interview, Karina states that she sees her porn web mistress occupation as a normal wage-generating job. However, in her musical performance, in which she enacts her web activities, the lyrics are underscored by dark, sinister music. Similarly, Rebekah testifies inher interview that she was meant to do what she does, she loves it and does notfeel exploited; her music video, however, portrays her as purely a commodity formale pleasure. Some characters even perform multiple identities in each mode. For instance, Kelly is interviewed and filmed in different locations, including public, domestic and professional locations, and she has several musical scenes in whichshe performs different types of characters (Figure 1). In the first, we even see heralongside her younger alter ego, played by a younger actress. 
This juxtaposition of multiple identities is manifest not only through mise-en-scène and body language, but also through the idiolect. Accounting for the particularity of a human being's distinctive and unique use of language, including tone, accent, pitch, word choice and phraseology, the idiolect is an essential element in the mediation of character subjectivity in Hill's films. ${ }^{17}$ The characters' non-professionaland often out-of-tune singing voices reveal the performative process by subverting the artifice of music videos; they also render the characters more individual and memorable. Their untuneful or mistimed singing suggests their completelack of vocal abilities, each in their own particular way (the exception is Michelle, whose conventionally pleasing singing voice is in fact the least memorable). Hill himself has admitted in a Q\&A that some characters in Pornography: The Musical sing like 'strangled cats', declaring that he does not choose characters based on their singing skills but on their stories. ${ }^{18}$
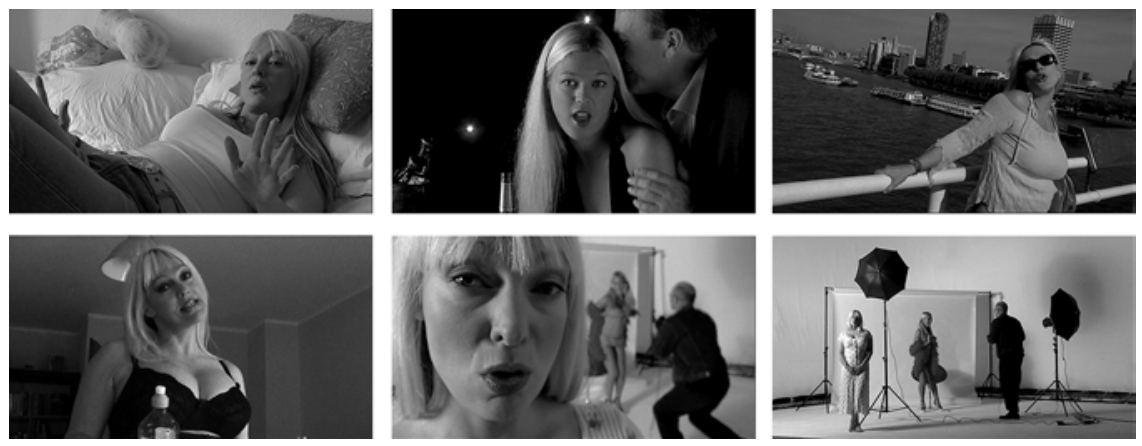

Figure 1 Kelly's multiple identities.

The ambivalence arising from the constant oscillation between documentary and music video, and between the character's multiple identities, creates a complexcharacter particularity of nuances, contradictions and layers, preventing the formation of schematic character roles that adhere to the binaries of the 'glitz-and-glamour-star' orthe'exploitedand-objectified-female'. Togetherwiththelackofconventionalplot structures and narrative exposition, this ambiguity surrounding the characters and their lives results in the audience perceiving the unique and distinct subject, instead of the schematic 'other'. The spectator is preoccupied with momentary embodiedexperience rather than trying to piece together characters' motivations, or beingdistracted with processing factual information about their lives and the industry. Hence, these subjective, momentary and ambiguous 
performances (whether sung or spoken) preclude the formation of universal representations or totalising arguments about sex workers or the porn industry. Although the characters belong to thatsocially marginalised industry, they are not metonyms for it. Rather, they exist asparticular and complex human beings in their own right.

\section{Reflexive Authorship}

Marginality in Pornography: The Musical does not only relate to common social conceptions about the porn industry, but also to the experimental character of its documentary form and its unusual impact on spectatorship. Hill's signature style is the hybridity of documentary and musical (or music video) - two seemingly incompatible genres that fulfil almost opposite ontological and epistemological functions, the former traditionally representing authenticity and the dissemination of factual information, and the latter representing pretence and embodied entertainment.However, Hill is careful not to completely blend the two; instead, he constantlyswitches between them. In terms of the narrative, this oscillation between opposite modes of authorial expression and spectatorial address reflects the aforementioned diegetic unity and particularity of each segment, and counteracts any tendency towards the coherence of a formulaic plot trajectory. This switching also reconfigures the schematic cognition necessary for the spectator to coherently categorise the documentary based on past viewing experience. ${ }^{19}$ After all, the modus operandi of non-diegetic sung interludes sprinkled into film narratives is usually only found in musicals, not non-fiction films. Challenging past viewing schemas may even be conducive to reconfiguring stereotypes about sex workers - a hypothesis supported by the episodic structure itself. Narrative comprehension relies on the activation of twotypes of past knowledge: 'generic' and 'episodic' 20 Genericknowledge is based on schematic scripts and stereotypes, both of which are informed by the pastconsumptionof formulaic, plot-driven narratives, whileepisodicknowledge is based on individual episodes experienced in the past at a particular time and place. Hence, a narrative made up of unique, momentary experiences without a generic plot structure, activates episodic knowledge and impedes the activation of genericknowledge. Italsoaddsepisodic knowledge, devoid ofstereotypes, to the spectator's knowledge structure and may inform how they view documentary films on the subject in the future.

Hill's performative act of constant switching is highly reflexive and is perceived as such by 
the viewer. According to Jay Ruby, true reflexivity constitutes not only the open display of the filmmaking process but the deliberate exposition of 'underlying epistemological assumptions that caused [the filmmaker] to formulate a set ofquestions in a particular way' for the audience. ${ }^{21}$ In Pornography: The Musical, this occurs in the collage of two seemingly incompatible genres, which playfully exhibits Hill's performativity and invites conjecture about his purpose in usingthis format. In this regard, the film's beginning is interesting. Film beginningsgenerally involve the spectatorial activity of parsing by comparing filmic cues with existing cognitive schemas, based on past viewings of similar films. ${ }^{22}$ This provides a frame of reference against which to measure developments in the filmas a whole. ${ }^{23}$ As Pornography: The Musical starts with the main title and a brief interview with Kelly, the audience is invited to expect a conventional documentary on the topicof pornography. ${ }^{24}$ This priming also raises expectations of the appearance of thesort of schemas found in the aforementioned films. However, Kelly's interviewis quickly followed by her first musical performance, which immediately defies expectations of conventional documentary forms. This sudden switch is indicative of all of Hill's musical documentaries and reveals a deliberate choice that firmly places the filmmaker's performance as a mediating catalyst between spectator and characters; it is a bifurcated exchange between the spectator and the author, and the spectator and the characters. This switch also results in a sudden deconstructionand reflexive awareness of the expectations of conventional TV documentaries. As Armitage, who wrote the lyrics, puts it, anything that 'jolts the audience and wakes them up' is worth trying. 25

These moments that 'jolt the audience' through the mixing of two apparently opposing epistemic modes of address - documentary factuality and music-video artifice confound the viewer's expectations of conventional documentary aesthetics and of a film in the tradition of other documentaries or cultural products related to pornography. What is usually portrayed as the grim and exploitative reality of the sex industry (as in The Dark Side of Porn) is relayed here through a highly stylised and titillating mise-en-scène that is neither judgemental nor valenced, but simplyvisually and aurally intriguing. Several other documentaries, such asSex: The Annabel Chong Story and Thinking XXX, also feature stylised settings but only as part of the pro-filmic world in which places (for example, strip bars) and situations (e.g. photo and film shoots) are simply observed. In stark contrast, Pornography: The Musical's stylised settings have been overtly constructed for the sole purpose of the film 
and the spectator's consumption. Artifice and performance are no longer simply an illustration or backdrop, but are foregrounded and thematised.

The correlation between the spectator's unmet expectations in terms of documentary style/genre and the representation of porn politicises Hill's authorial reflexivity beyond questions of aesthetics. Nichols explains that 'political reflexivity' comprises unexpected modes of representation that provoke an awareness of therepresentation of social organisation and the assumptions that support it, framing localised audience experience with a wider socio-cultural experience and incorporating the spectator as a reflective social actor. ${ }^{26}$ This socio-cultural awareness may well prompt the audience to question and reconfigure ossified stereotypes aboutpornography, aswatching Pornography:The MusicalinevitablychallengesBhabha's fixityofstereotypes.

This wide-ranging exchange between filmmaker and spectator is best summed up by Paget and Roscoe, who observe that:

Hill's work unsettles expectations and invites us to view the relationship between the documentary image and the 'real world' afresh. These works ask us to think about how we evaluate documentary truth and the place of testimony within it. Their innovatory power is poised especially awkwardly between creativity and commodity. 27

Pornography:The Musical is very much a rendition of, and a reflection, on pornography as a commodity and its consumption. It does not simply discuss the aspect of commodification; it embodies it for the spectator. Commodification as an embodied metaphor is perhaps the most ubiquitous element of the viewer's experience ofthis film. Drawing on George Lakoff's and Mark Johnson's concept of cognitive metaphors, Kathrin Fahlenbrach argues that metaphors created through audio-visual aesthetics rely on bodily based image schemata that are first of all perceived physically - this holds especially true for Pornography: The Musical's metaphor of commodifying the human body. ${ }^{28}$ Through their direct address, the singing performances position the viewer into the role of a consumer, reminiscent of webcam and gonzo pornography. This is confirmed by reviewers, who have criticised the film for being as pornographic as the topic it attempts to examine. ${ }^{29}$ Although these reviewers have obviously not grasped the film's satirical dimension, their 
critique implicitly verifies Hill's own performative act of playfully fetishising pornography as a commodity. Therefore, the film can be seen to hold up a mirror to the audience's own consumption practices through a variety of aesthetic means, such as the use of low-budget yet flashy sets, hyperbolised and amateurish performances, filming the camera filming the pornographic act (Figure 2) and revealing the fetishised (and fetishising) frame (Figure 3). This over-stylisation is typical for music videos and informs the embodied reception of metaphors. As Fahlenbrach asserts, the dense network of affective audio-visual stimuli that isimmediately forced upon the spectator in music videos creates a basic physical and cognitive experience in which thematic associations are somatically felt rather than consciously processed. ${ }^{30}$

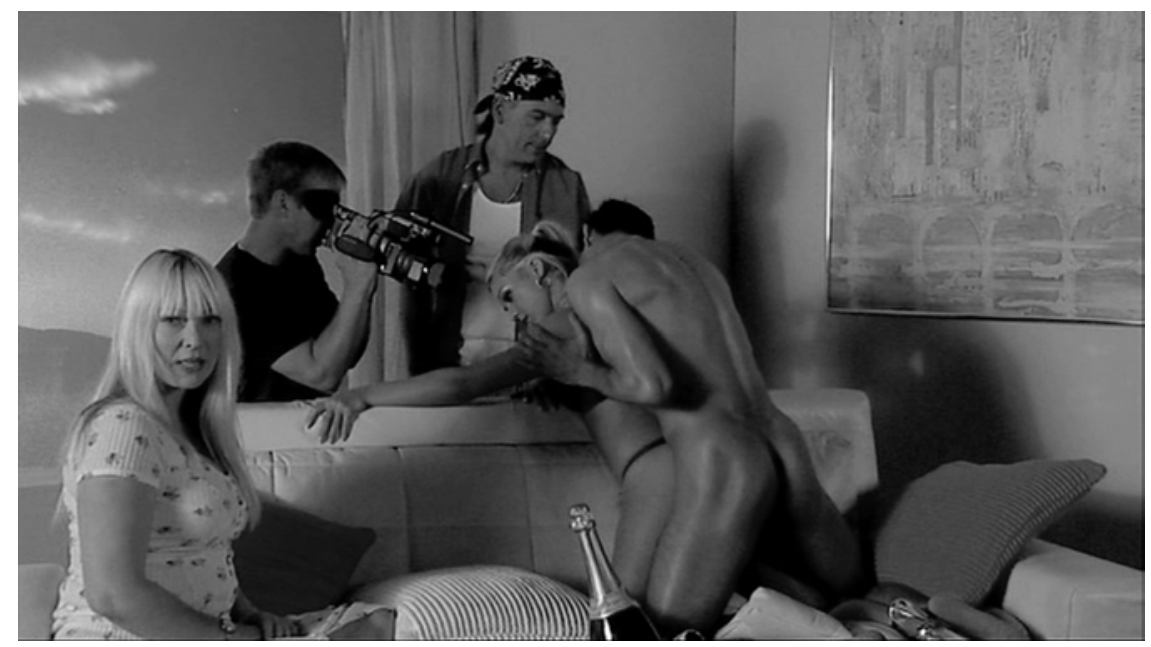

Figure 2 The camera filming the camera filming the pornographic act.

Nichols confirms that performative documentaries do not address the spectator 'with commands or imperatives necessarily, but with a sense of emphatic engagement', turning the viewer, ratherthan the historical world, intothe primary referent. ${ }^{31}$ The inhibition ofindexicalconcernsis aided bythecharacters' relative obscurity. Astheyare littleknownin the porn industrycompared with more popular, visible or commercially successful names, the average spectator is bound to have no referential knowledge about the real-life characters, and thus no benchmarks against which the film's veracity could be evaluated. 


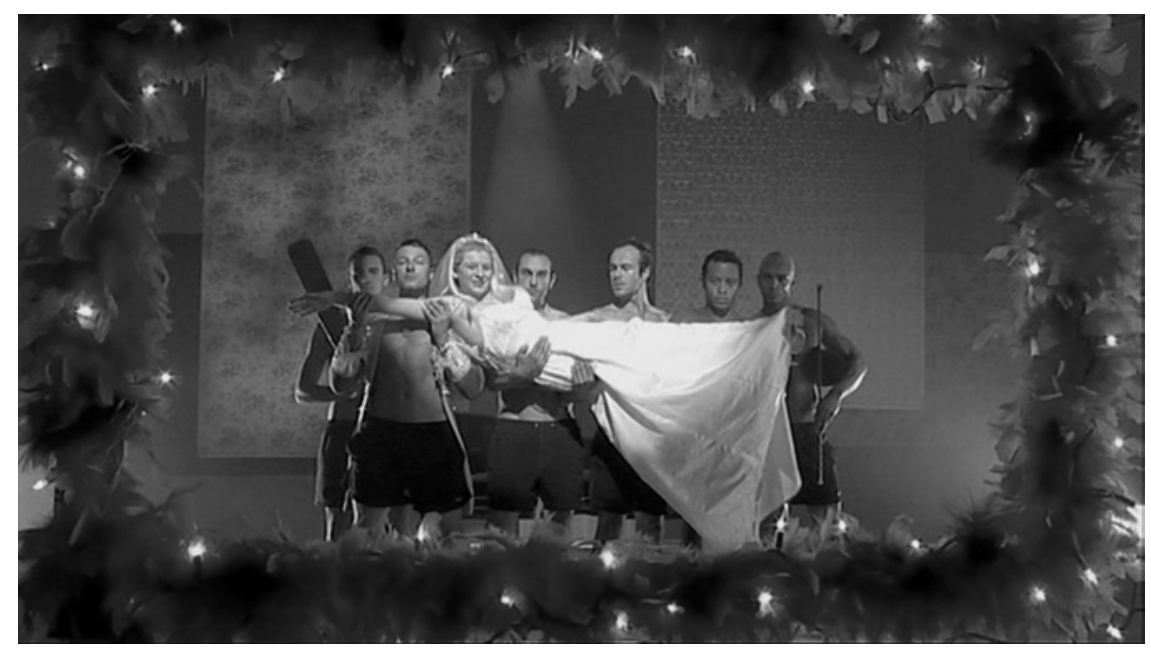

Figure 3 The fetishised frame.

\section{Conclusion}

Performativity operates on multiple levels in Pornography: The Musical and is key to understanding the film's spectatorship in relation to the narrative and aesthetic depiction of the characters and its overt authorship. Performative acts revolve around the mediation of subjectivity and embodied experience, but their real nucleus is the sense of 'ambiguity'. Ambiguityis a much-discussed theme in performativity theory and is especially relevant to 'gender-bending' performances that seek to overcome stereotypical gender binaries. ${ }^{32}$ । have argued elsewhere that a general sense of ambiguity, not only in relation to the actual characters but also to the entire viewing experience, is conducive to overcoming the stereotypical expectations that framespectatorship. ${ }^{33}$ Pornography: The Musicalis imbued with a plethora of ambiguities that respectively violate, overcome, blend, reflexively problematise and playfully exhibit orthodox binary opposites, most notably:

- playful style v. serious content

- documentary sobriety v. musical artifice

- creative artistry v. banal commodification

- experimental v. mainstream

- woman-as-displayed-object v. woman-as-active-performer

- consumers of porn v. performers of porn 
- distanced spectator v. immersed participant

- the pornographic 'others' v. the moral 'us'

Performative documentaries also have the capacity to transcend the boundary between the socio-cultural macrocosm and the individual microcosm. As Nichols explains, these types of idiosyncratic films merge concerns about the 'social' and the 'subject', thus embedding affective experience within a wider socio-cultural aware- ness and mediating the 'socialsubjectivity' of communities marginalised through under-or misrepresentation. ${ }^{34}$ Nevertheless, Hill's film does not only inhabit a marginal or liminal space that is constantly renegotiated through performative acts; the film itself is one of the most marginal in his oeuvre. It is not regarded as an iconic musical documentarylike his DrinkingforEngland or Feltham Sings, both of which enjoyed commercial and critical acclaim. Its underwhelming reception may be a result of the ambiguity and marginality besetting the characters, narrative and authorial treatment. And yet it is exactly these elements that validate its social contextand themes, resultinginone ofHill's mostconceptually sophisticated works.

For example, in Feltham Sings, which stylistically is almost identical to Pornography: The Musical, the singing can be seen as symbolising a desire for escapism, an expression of the dreams, desires and regrets of the young prison inmates. In Pornography:TheMusical, however, thesongs' themesand the 'candour' of thelyrics have to be taken with a pinch of salt, since it is 'just another' performance by the porn actresses who make a living out of role-playing. Nevertheless, it is exactly this ambiguity of expression that resonates with the topic of pornography and porn performances. This latent thematic layer is brought to the fore byHill's aforementioned playful commodification of his own film as a parallel to porn films themselves, positioning the spectator in the embodied, and perhaps uncomfortable, position of a consumer. Feltham Sings and Hill's other films lack this thematic complexity and spectatorial address.

In any case, when challenging the binary definitions, schematic knowledge and totalised perceptions of sex workers, the film's ambiguity appears to be a prerequisite for overturning the perceived otherness of sex workers, who are them- selves marginalised through the perpetuation of stereotypes. The film's playfuldeconstruction of the fixed symbolic meanings permeating narrative formulasand social stereotypes is arguably a commentary on the documentary representation of human subjects in general. 
Somewhat paradoxically, the film's overt ambiguity, stylistic poetry, performativity and reflexivity (elements that are traditionally seen to call into question the very factuality and sobriety of documentary) overturn fixed, totalised and schematic knowledge patterns, and by so doing,they provide a more candid, particular and nuanced portrayal of porn industry workers. After all, the particularity of the human subject itself comprises anamalgamation of multi-layered identities, uncertainties, doubts and a plurality of meanings. 35

\section{Notes}

1 Maxine Baker, Documentary in the Digital Age, Boston: Focal Press, 2006, p. 169.

2 'Pornography: The Musical (2003)', Century Films, n.d., www.centuryfilmsItd.com/portfolios/pornography-the-musical.

3 See, for example, Baker, Documentary in the Digital Age; Derek Paget and Jane Roscoe, 'Giving Voice: Performance and Authenticity in the Documentary Musical', Jump Cut 48(2006), www.ejumpcut.org/archive/jc48.2006/MusicalDocy/; Peter Lee-Wright, The Documentary Handbook, London: Routledge, 2010.

4 Charles Percy Snow, The Two Cultures: And a Second Look - An Expanded Version of The Two Cultures and the Scientific Revolution, Cambridge: Cambridge University Press, 1962.

5 Judith Butler, Gender Trouble: Feminism and the Subversion of Identity, New York: Routledge, 1990.

6 Judith Butler, Bodies That Matter: On the Discursive Limits of 'Sex', New York: Routledge, 1993, p. 124.

7 Paget and Roscoe, 'Giving Voice'.

8 Bill Nichols, Introduction to Documentary, Bloomington: Indiana University Press, 2001, p.131. Nichols'suse of 'performativity' differs from Butler's in thatherefers to documentaries, where performativity is overtly expressed by the screen characters, which makes his 'performative documentary mode' relevant to the analysis of musical documentaries.

9 Michael Renov, The Subject of Documentary, Minneapolis: University of Minnesota Press, 2004, p. 148.

10 Cited in Kate Nash, 'Documentary-for-the-Other: Relationships, Ethics and (Observa- tional) Documentary', Journal of Mass Media Ethics 26:3 (2011): 232-3.

11 Homi Bhabha, 'The Other Question ...', Screen 24:6 (1983): 18.

12 Richard Dyer, 'Stereotyping', in Meenakshi Gigi Durham and Douglas M. Kellner (eds), 
Mediaand CulturalStudies:Keyworks, Malden: Blackwell, 2006, p. 355.

13 See, for example, Alexis Tan, Francix Dalisay, Yunying Zhang, Euon-Jeong Han and Mariyah M. Merchant, 'ACognitive Processing Model of Information Source Use and Stereotyping: African-American Stereotypes in South Korea', Journal of Broadcasting \& Electronic Media 54:4 (2010): 572.

14 Bill Nichols, Ideology and the Image: Social Representation in the Cinema and Other Media, Bloomington: Indiana University Press, 1982, p. 211.

15 Greg M. Smith, 'The Segmenting Spectator: Documentary Structure and The Aristo-crats', Projections 1:2 (2007): 87-8.

16 Richard Dyer, 'Entertainment and Utopia', in Bill Nichols (ed.), Movies and Methods - Volume 2, Berkeley: University of California Press, p. 229.

17 Paget and Roscoe, 'Giving Voice'.

18 From the Q\&A session at the event 'Performativity on the Margin: Brian Hill Documen- tary Masterclass', held at the University of West London, 24 November 2015.

19 See, for example, Ib Bondebjerg's articles: 'Narratives of Reality: Documentary Film and Television in a Cognitive and Pragmatic Perspective', Nordicom Review 1(1994):65-87, and 'Cosmopolitan Narratives. Documentary and the Global “Other"', Nordicom Review 35 (2014): 53-67.

20 See Arthur C. Grasser, Brent Olde and Bianca Klettke, 'How Does the Mind Construct and Represent Stories?, in Melanie C. Green, Jeffrey J. Strange and Timothy C. Brock (eds), Narrative Impact:Social and Cognitive Foundations, Mahwah: Lawrence Erlbaum Associates, 2002, p. 244.

21 Jay Ruby, 'The Image Mirrored: Reflexivity and the Documentary Film', in Alan Rosenthal and John Corner (eds), New Challenges for Documentary, 2nd edn, Manch- ester: Manchester University Press, 2005, p. 35.

22 Bondebjerg, 'Narratives of Reality', p. 75.

23 David Bordwell, Making Meaning:Inference and Rhetoricin the Interpretation of Cinema, Cambridge: Harvard University Press, 1989, pp. 189-90.

24 It could be argued that the word 'musical' in the main title and the singing performances mentioned in other paratexts, such as trailers and synopses, give away Hill's style, but the unfamiliarity with singing performances in non-fiction means the initial parsingprocess cannot retrieve comparable data from past viewings.

25 Quoted in Baker, Documentary in the Digital Age, p. 161. 
26 Nichols, Introduction to Documentary, p. 130.

27 Paget and Roscoe, 'Giving Voice'.

28 Kathrin Fahlenbrach, 'The Emotional Design of Music Videos. Approaches to Audio- visual Metaphors', Journal of Moving Image Studies 3:1 (2005): 24.

29 See Baker, Documentary in the Digital Age, p. 169.

30 Fahlenbrach, 'The Emotional Design of Music Videos', p. 27.

31 See Bill Nichols, Blurred Boundaries: Questions of Meaning in Contemporary Culture, Bloomington: Indiana University Press, 1994, p. 94.

32 Elisabeth Kirtsoglou, For the Love of Women: Gender, Identity and Same-Sex Relations in a Greek Provincial Town, London: Routledge, 2004, p. 34.

33 Catalin Brylla, 'Spectatorship and Alternative Portrayals of Blindness', in Catalin Brylla and Helen Hughes (eds), Documentary and Disability, London: Palgrave Macmillan, 2017.

34 See Nichols, Introduction to Documentary, p.133.

35 Nash, 'Documentary-for-the-Other', pp. 237-8. 